\title{
KAJIAN SIMBOLIK KRESNA WANDA RONDON \\ PADA WAYANG KULIT PURWA GARAPAN SAIMONO AGUS SUBIANTORO
}

\author{
Yuni Prastika Sari \\ Fakultas Seni Rpa dan Desain ISI Surakarta \\ yuni_prastika@gmail.com \\ Nunuk Nur Shokiyah \\ Fakultas Seni Rpa dan Desain ISI Surakarta \\ nunuk@isi-ska.ac.id
}

\begin{abstract}
This study examines focus on the symbolic meaning of shadow puppet Kresna wanda Rondon produced by Saimono Agus Subiantoro and background creation. This research is descriptive qualitative research. The validity of the data using triangulation data. Analysis of the data used is the analysis of the interaction with Saimono directly to find out the background of the creation of the work. To explain the meaning of the symbolic use of interpretation through symbols theory approach Susanne K. Langer.

Keywords: Symbol, Krishna Wanda Rondon, Saimono
\end{abstract}

\section{ABSTRAK}

Penelitian ini fokus mengkaji tentang makna simbolik wayang kulit Kresna wanda rondon yang digarap oleh Saimono Agus Subiantoro dan Latar belakang penciptaannya. Penelitian ini adalah penelitian kualitatif deskriptif. Validitas data menggunakan triangulasi data. Analisis data yang digunakan adalah analisis interaksi dengan Saimono secara langsung untuk mengetahui latar belakang penciptaan karya. Untuk menjelaskan makna simbolik menggunakan interpretasi melalu pendekatan teori simbol Susanne K. Langer.

Kata kunci: Simbol, Kresna Wanda Rondon, Saimono

\section{PENDAHULUAN}

Penelitian ini merupakan penelitian yang mengkaji makna simbolik dan karakter dari Figur Sri Batara Kresna berwanda rondon atau Krisnha dalam versi Mahabaratha India. Legenda Hindu pada kitab Purana dan Mahabharata menyatakan bahwa dia adalah putra kedelapan Basudewa dan Dewaki, bangsawan dari kerajaan Surasena, kerajaan mitologis di India Uta- ra dan inkarnasi dari Dewa Wisnu. Figur Kresna dikenal sebagai raja Dwarawati. Dalam perwayangan Ja wa Kresna merupakan putra kedua dari tiga bersaudara, kakaknya bernama Baladewa (Balarama) dan adiknya dikenal sebagai Sembadra (Subadra).

Kresna wanda rondon merupakan wanda Kresna dalam suasana agung, hal ini berkaitan dengan jiwa kepemimpinan Kresna 
yang bijaksana dan berwibawa. Sementara di Indonesia sendiri jarang memiliki sosok pemimpin yang dapat dijadikan panutan. Mulai dari pemimpin rumah tangga hingga pemimpin Negara. Sehingga Kresna wanda rondon ini dapat dijadikan panutan sebagai seorang pemimpin yang baik dan mampu. Latar belakang penciptaan wayang kulit Kresna merujuk pada salah satu bentuk pelestarian seni tradisi yang mungkin saja menyimpan banyak nilai kearifan lokal yang dilakukan oleh Saimono, Saimono sendiri merupakan seorang pelestari tatah sungging wayang yang memiliki banyak pengalaman dalam bidang tatah sungging wayang. Sehingga sekiranya penting untuk mengkaji tentang Kresna wanda rondon tersebut. Rumusan masalah yang terbentuk dari permasalahan tersebut adalah bagaimana latar belakang penciptaan karya wayang Kresna wanda rondon dan bagaimana makna simbolik wayang kulit Kresna wanda rondon garapan Saimono.

Proses garap karya yang dilakukan Saimono menggunakan pa -kem pembuatan tatah sungging wayang yang terbagi menjadi lima tahap proses garap, antara lain:

1. Menanggalkan bulu dari kulit
2. Membuat pola wayang pada kulit

3. Menatah pola dan bedhahan wayang kulit

4. Pewarnaan sungging wayang kulit

5. Memasang gapitan dan tuding wayang

Sedangkan teori yang digunakan untuk menganalisa pemaknaan simbolik dari Kresna wanda rondon adalah teori tentang wanda, wanda sendiri Secara sederhana wanda adalah ekspresi terutama pada wajah dan bentuk tubuh dari tokoh wayang yang mengungkapkan watak dan kepribadian dari tokoh wayang tersebut untuk mendukung suasana-suasana tertentu dalam sebuah adegan. Wujud figur wayang tidak sekedar melukiskan tokoh tetapi juga melukiskan karakter. Wanda juga dapat dikatakan sebagai karakter yang muncul kepermukaan. Teori kedua adalah tentang unsur visual yang terdiri dari garis, bangun(shape), tekstur, warna, ruang, komposisi, dan proporsi. Serta pemaknaan perabot pakaian Kresna menurut Bambang Suwarno dan teori tentang simbol Suzanne K. Langer. Langer menjelaskan tentang symbol of feeling, digunakan pendekatan teori ini untuk pemaknaan simbol-simbol yang 
terkandung pada perabot yang ada pada wayang kulit Kresna wanda rondon garapan Saimono.

Jenis penelitian ini adalah penelitian kualitatif-deskriptif, berlokasi di Surakarta tempat wayang Kresna tersebut disimpan, serta beberapa lokasi lain tempat penulis melakukan observasi dan wawancara, salah satunya adalah di rumah Dalang Bambang Suwarno . Sumber data primer sendiri merupakan objek wayang Kresna wanda rondon dan Saimono Agus Subiantoro sebagai pembuat wayang tersebut, dari sumber primer memperoleh data tentang latar belakang penciptaan dan proses garap karya. Observasi dan wawancara yang dilakukan dengan nara sumber lain seperti dengan Agus Ahmadi memperoleh tentang pemaknaan warna, dan Bambang Suwarno tentang makna simbolik dari perabot Kresna. Validitas data menggunakan triangulasi data, sedangkan analisis -nya menggunakan interaksi analisi dan interpretasi analisis dengan pendekatan teori simbol Suzanne K.Langer.

\section{PEMBAHASAN}

Saimono merupakan seorang pelestari Tatah Sungging wayang yang sudah memiliki banyak peng -alaman dan penghargaan, untuk membuat karyanya, Saimono memiliki alasan dan tujuan untuk tetap melestarikan seni tradisi di Indonesia, khususnya wayang kulit. Saimono membuat wayang kulit Kresna tesebut bertujuan untuk melestarikan karya seni dan budaya khususnya wayang yang adi luhung peninggalan dari nenek moyang yang perlu di uri-uri, dipertahankan dan dikembangkan sesuai dengan keadaan zaman. Maka alasan tersebut dapat dikategorikan sebagai konsep penciptaan non-visual.

Wayang kulit purwa merupakan suatu kesenian yang masuk dalam beberapa kategori, seni rupa dengan teknik pewarnaan sungging nya, kriya seni dengan teknik tatah, dan seni pertunjukan dengan naskah drama serta musik yang mengiringinya. Pembuatan karya wayang Kresna wanda Rondon juga melalui serangkaian proses, pakem dan ritual pembuatan. Pakem selalu digunakan untuk membuat karya yang baik dan maksimal. Seperti pakem yang harus menatah dari bawah terlebih dahulu kemudian berangsur keatas untuk meningkatkan apa saja harapan yang membuat, dan ritual puasa yang dilakukan tidak lebih agar lebih konsentrasi selama proses menatah 
kulit, serta nglerem untuk beristirahat sejenak dan kemudian dilanjutkan dengan proses pembedah -an wajah wayang. dilanjutkan dengan proses pewarnaan sungging dan gapitan. Semua tradisi yang dijalankan merupakan upaya dalam konservasi dan revitalisasi wayang kulit purwa yang mulai jarang peminatnya dengan berjalannya waktu. Revitalisasi sendiri termasuk dalam kosep visual yang dipakai oleh Saimono. Menatah dan menyungging wayang memerlukan kesabaran dan ketekunan, serta dapat digunakan sebagai latihan menjaga emosi.

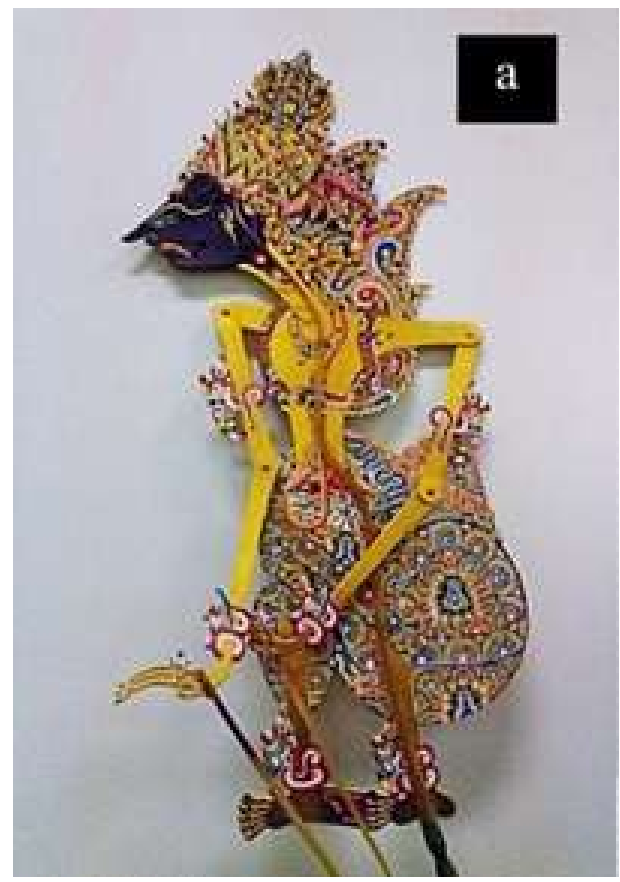

Gambar 1.

Kresna Wanda Rondon versi Saimono Agus Subiantoro

(Foto oleh Yuni Prastika Sari di Surakarta, 2017)
Kresna Wanda Rondon sendiri digunakan untuk adegan jejer pertama adegan kedhaton pathet Nem. Saat jejer pertama pathet nem, adalah adegan dengan suasana kewibawaan dalam kerajaan. Sedangkan ciri-cirinya adalah wajah agak menunduk, posisi mata agak tegak, posisi leher condong memanjang, dada tegak, pundak tegak, badan berwarna prada emas dengan bentuk agak gemuk. Wayang Kresna wanda rondon ini adalah merupakan karya wayang Kresna yang dibuat oleh Saimono tahun 2014. Bentuk Kresna tersebut adalah seperti gambar 1 berikut:

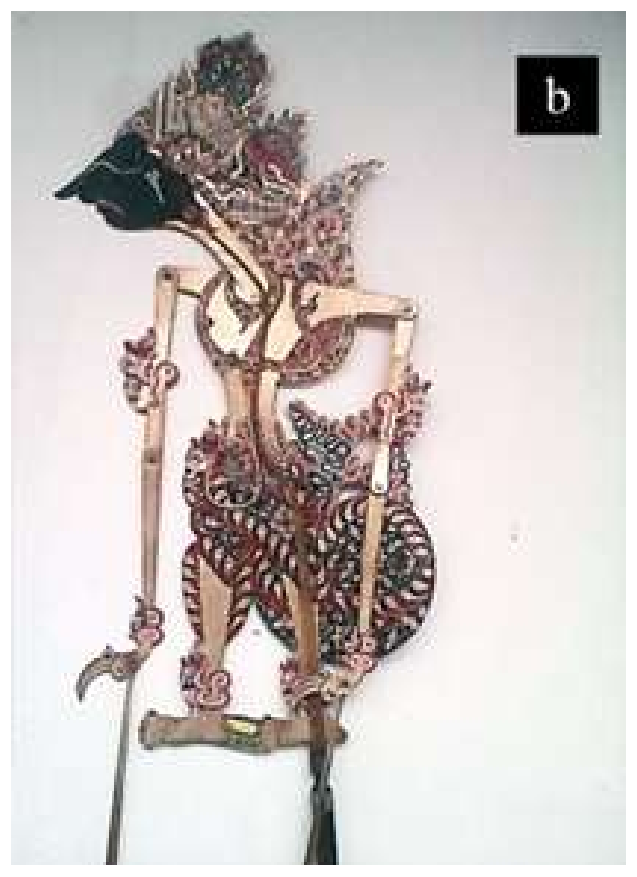

Gambar 2.

Kresna Wanda Rondon versi Bamban Suwarno

(Foto oleh Mutiara Putri Dhamastuti di Surakarta, 2017) 
Bentuk visual wayang Kresna yang Saimono buat jika diperhatikan, terdapat perbedaan pada karya wayang Kresna wanda rondon yang digarap oleh Bambang Suwarno, perbedaan dari wayang tersebut hanyalah sebagai data yang menjelaskan tentang bagian mana yang menarik dari wayang yang dibuat Saimono dan wayang yang dibuat oleh Bambang Suwarno. Jika dirujuk dari ciri asli wayang Kresna wanda rondon yang asli, maka sebenarnnya garapan Bambang Suwarno yang lebih mendekati. Tetapi garapan Saimono ini menjadi unik karena menambahkan sedikit kreasi dalam bentuk dari wayang Kresna wanda rondon tersebut. Pada perabotnya terbagi menjadi:

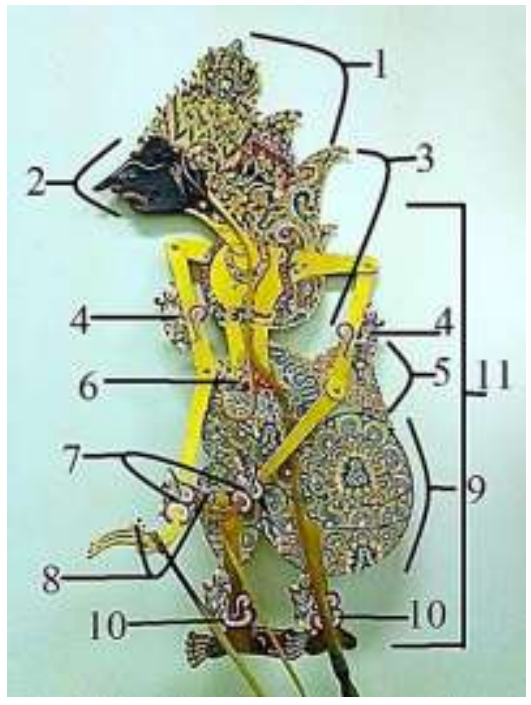

Gambar 3.

Bentuk Visual Kresna Wanda Rondon (Foto oleh Yuni Prastika Sari, 2017)
Pertama, Makuthan kencana karo jamang mas susun tiga, karawista, garuda mungkur utah-utahan kinarawistha, udawala ngiras tetali lan sumping surengpati.

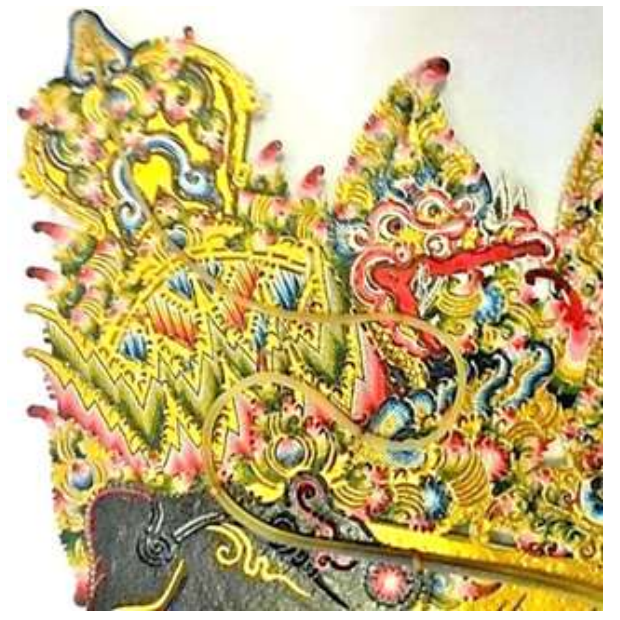

Gambar 4

Makuthan Kencana

(Foto oleh Yuni Prastika di Surakarta, 2017)

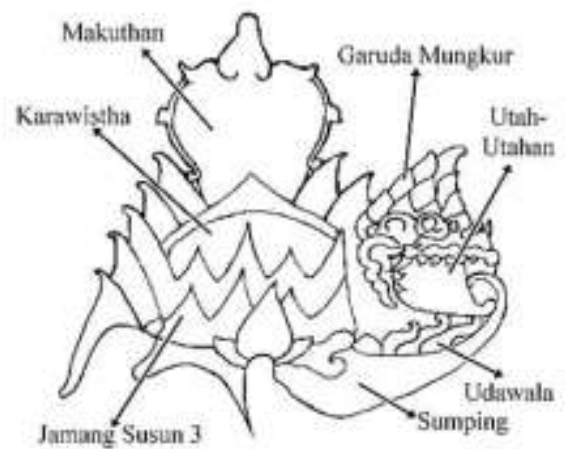

\section{Gambar 5}

Detail Bagian-Bagian Makhutan (Sketsa oleh Yuni Prastika Sari, 2017)

Makuthan adalah Mahkota dalam bahasa Indonesia, Kencana merupakan emas. Jadi makhutan kencana merupakan mahkota yang 
dilapisi emas. Jika dianalisis dengan teori Langer, secara simbolik mahkota merupakan perlambangan dari sebuah kekuasaan atau jabatan tinggi. Sedangkan pada ranah seni rupa, bentuk mahkota sering kali digunakan untuk mefetamorkan sebuah kekuasaan dengan mendistorsikannya. Warna ke -seluruhan yang digunakan adalah dominan warna emas, dengan nuansa merah, hijau, putih, jingga, hitam dan biru. Pada penjabaran warna sungging wayang kulit purwa sendiri. warna emas disimbolkan sebagai kewibawaan. Tetapi secara nyata emas merupakan simbolik dari kemewahan. Sedangkan untuk pemaknaan keseluruhan warna berarti bermakna agung, berani, tenang, jujur, masyur, tegas dan kebenaran. Makna warna tersebut mengacu pada wanda wayang Kresna Rondon dan sifat-sifat Kresna sebagai raja yang bijaksana.

Kedua, Irung longok, mata liyepan, rupa ireng, lan suweng surya/ candra kalangan.

Suweng adalah anting-anting, sedangkan surya adalah matahari, dan candra adalah bulan. Makna simbolik dari suweng surya dan candra kalangan adalah bahwa seorang raja harus memiliki 2 pencerahan untuk rakyatnya. Surya adalah simbolis kekuatan dan semangat, seorang raja haruslah kuat dan menguatkan rakyatnya, serta menjadi pribadi yang hangat dan bersemangat untuk rakyatnya. Sedangkan candra adalah pemaknaan dari keteduhan yang dimiliki seorang raja untuk rakyatnya, bijaksana dan menenangkan rakyatnya.

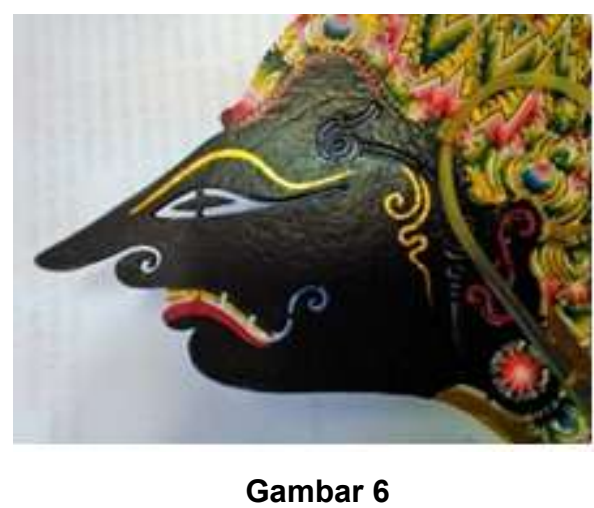

Rupa Wajah Kresna

(Foto oleh Yuni Prastika Sari di Surakarta, 2017)

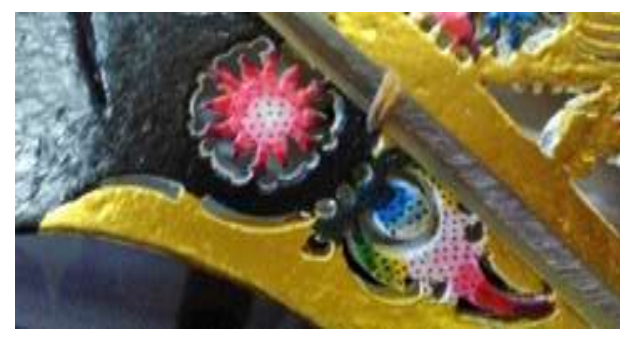

Gambar 7

Suweng Surya/ Candra Kalangan (Foto oleh Yuni Prastika di Surakarta, 2017)

Pemahaman Langer tentang symbol of feeling dapat diperbandingkan dengan kepercayaan pada matahari dipuja sebagai dewa, se- 
but saja seperti Hindu dengan dewa Suryanya, Shinto dengan amaterasunya, serta suku maya dengan pemujaan terhadap gerhana matahari. kenyataannya matahari memang memiliki banyak manfaat untuk semua mahkluk hidup.

Untuk pemaknaan secara menyeluruh warna hitam berarti tegas jika didasarkan dengan karakter Kresna sendiri. sedangkan menurut Saimono sendiri hitam berarti berwibawa. anting-anting matahari dan rembulan, seperti antinganting yang memiliki 2 sisi, Kresna wanda rondon juga memiliki sifatsifat seperti kuat, berani, bijaksana dan tenang disaat yang bersamaan. Tiga, Praba kencana lan kalung ulur-ulur.

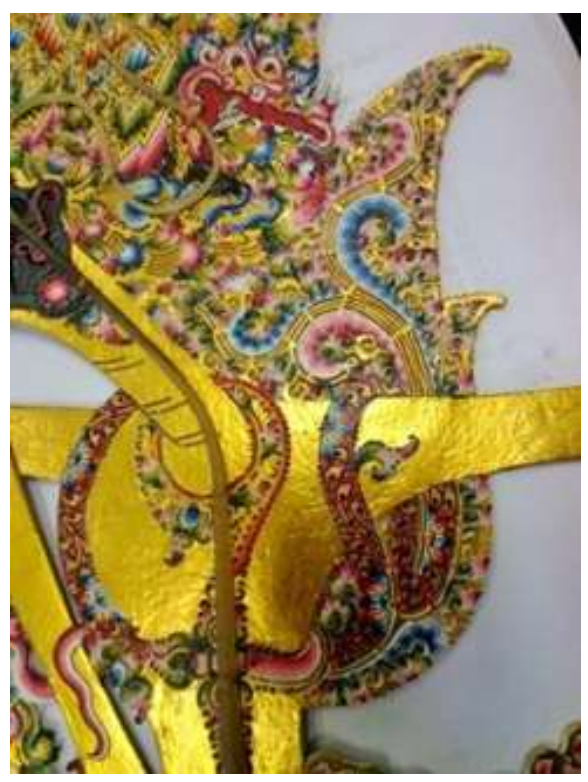

Gambar 8

Praba Kencana

(Foto oleh Yuni Prastika di Surakarta, 2017)

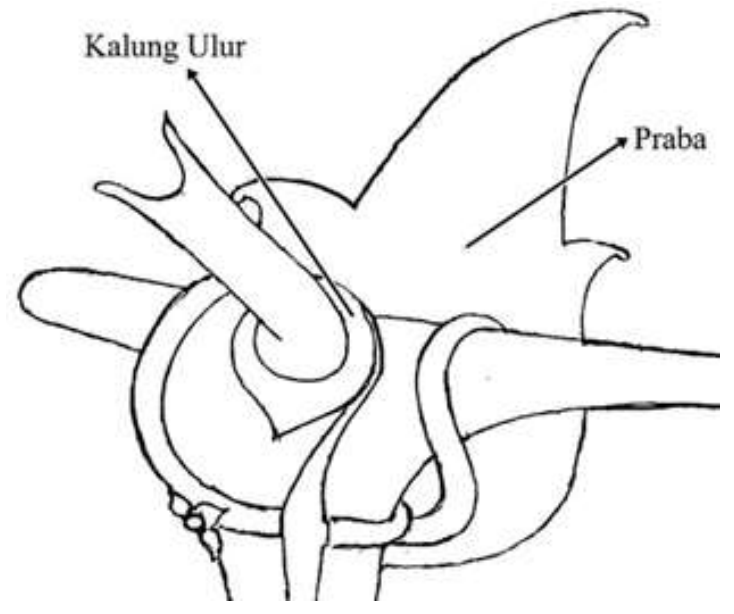

Gambar 9

Detail Praba dan Kalung Ulur (Sketsa oleh Yuni Prastika Sari, 2017)

Secara simbolik Bambang Su -warno mengatakan bahwa praba merupakan bentuk dari aura atau cahaya dari tokoh wayang tersebut. Praba kencana berarti cahaya keemasan. Maka dapat dikatakan Kresna wanda rondon memiliki aura yang bercahaya keemasan. Sedangkan konsep tentang makna warna emas sendiri memang berarti keagungan. Kalung ulur adalah kalung yang hanya dipakai oleh kalangan raja, kalung sendiri adalah perhiasan yang melingkari leher. Warna dari kalung ulur ini adalah warna merah pada bentuk ulur dan kuning pada kalungnya. Secara simbolik bidang kalung dan uluran pada wayang Kresna wanda rondon tersebut menunjukkan bahwa Kresna adalah dari kalangan raja. 


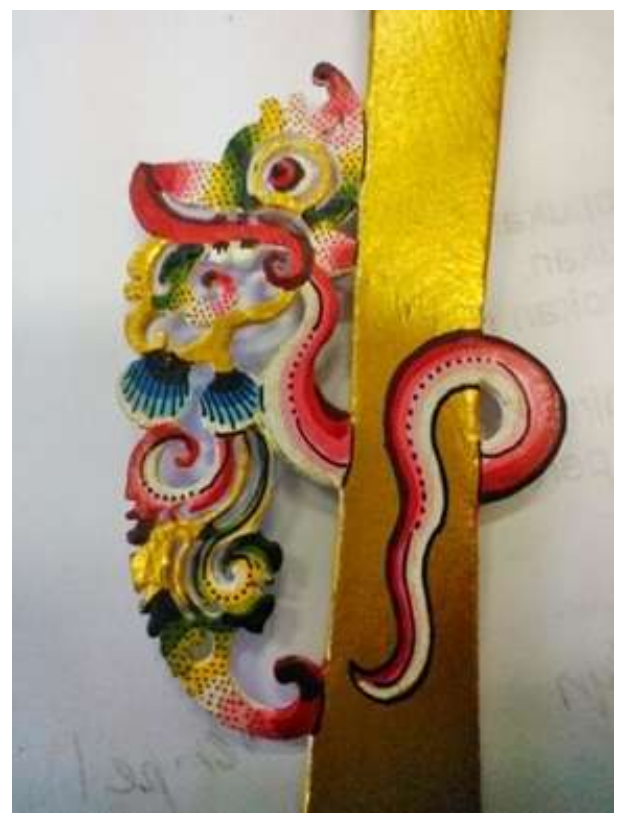

Gambar 10

Kelat bahu Nagamangsa

(Foto oleh Yuni Prastika di Surakarta, 2017)

Dalam teori tentang symbol of feeling oleh Langer, naga di beberapa daerah dan negara tertentu dianggap sebagai mahkluk yang istimewa. Seperti naga dalam kepercayaan Tionghoa, naga di kepercayaan Scotlandia sebagai Lochgnes. Pada beberapa kepercayaan naga dianggap hewan mitologi yang suci dan kuat, begitu juga dengan kepercayaan Hindu dan Budha yang diartikan sebagai lambang sejatining urip (kehidupan yang sejati). Seolah menggambarkan betapa sulitnya jalan berliku-liku yang harus ditempuh untuk mencapai tujuannya.
Kelatbahu dalam wayang kulit sendiri menunjukkan tingkat jabatan atau harkat dan martabat dari tokoh wayang tersebut. Pemaknaan simbolik dari kelatbahu nagamangsa adalah naga pada masingmasing lengan akan menjaga tokoh wayang tersebut. Seperti menggunakan pakaian perang dengan berbagai macam atribut pelindungnya, karena nagamangsa adalah visualisasi dari seekor naga.

\section{Kelima, Manggaran lan Bandono}

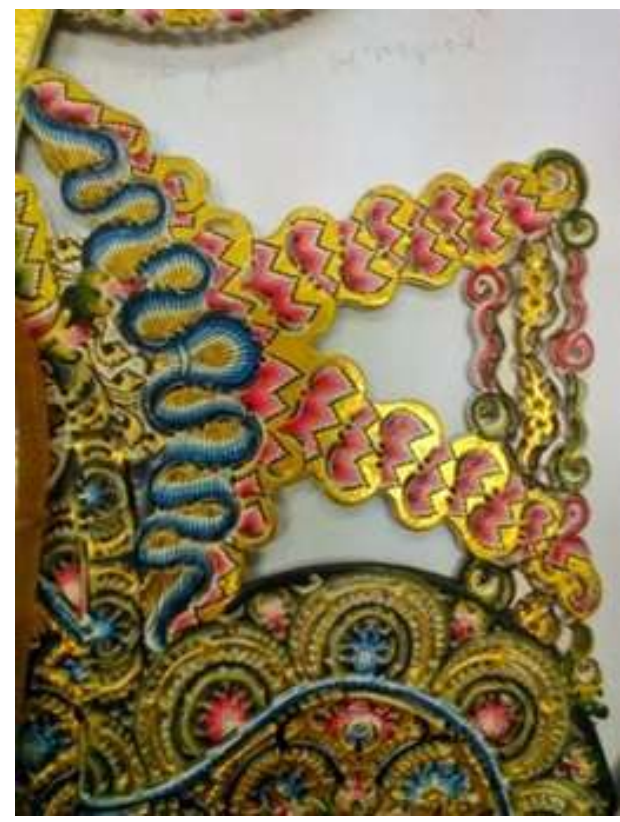

Gambar 11

Manggaran dan Bandono (Foto oleh Yuni Prastika Sari di Surakarta, 2017) 


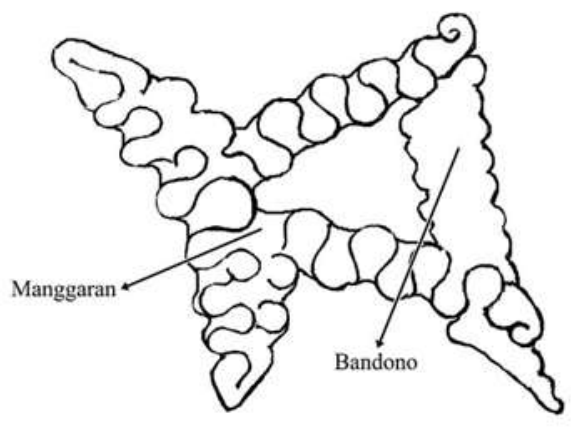

Gambar 12

Detail Manggaran dan Bandono (Sketsa oleh Yuni Prastika Sari, 2017)

Menurut Bambang Suwarno tentang Manggaran duwungu tinatah-tinatih renggo wangkingan warong koladran kandelen kamerekto, berarti manggaran adalah gambaran dari senjata, wangkingan adalah sarung keris, sedangkan kandelen adalah tubuh kerisnya. Manggaran secara filosofis dimaknakan sebagai simbol birahi seseorang. Birahi adalah semua jenis nafsu, termasuk nafsu makan, nafsu bekerja, dan sebagainya. Hingga perlunya manggaran seorang raja ditali dengan bandono dalam karakter wayang kulit purwa. Pada Kresna wanda rondon ini mesimbolkan bahwa Kresna dapat dengan baik menguasai segala nafsunya. Maka dipasangkanlah manggaran dengan Bandono, Bandono merupakan tali pengikat sembuliyan manggaran. Seperti yang disebutkan sebelumnya bahwa manggaran adalah simbolis dari birahi. Maka ban- dono simbolis dari pengikat dan penetralnya. Menurut bambang suwarno, semua raja yang menggunakan manggaran, maka harus ditutup dengan bandono.

\section{Keenam, Sabuk cindebinoro}

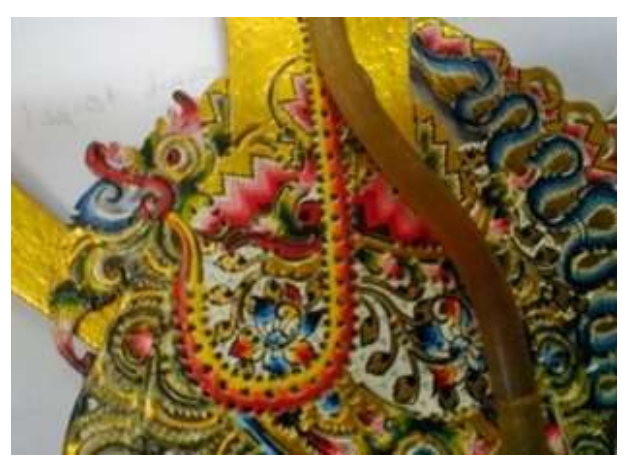

Gambar 13

Sabuk Cindebinoro

(Foto oleh Yuni Prastika di Surakarta, 2017)

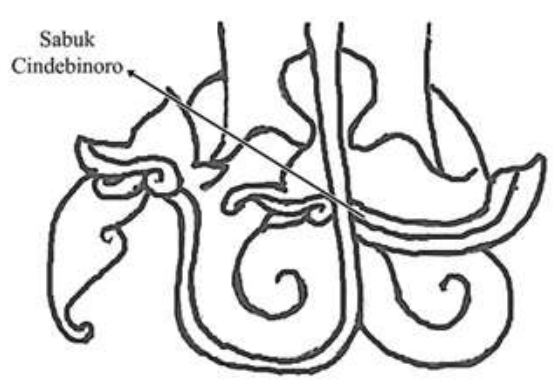

Gambar 14

Sabuk Cindebinoro

(Sketsa oleh Yuni Prastika Sari)

Menurut teori Langer tentang symbol of feeling, maka sabuk Sabuk adalah tali pengikat pada pinggang, sabuk adalah konsep tentang pengaman, seperti sabuk pengaman, dan penghargaan untuk olahraga tinju atau gulat. Sedang- 
kan menurut Bambang Suwarno cinde sendiri adalah sejenis obat un -tuk menyembuhkan penyakit biduran. Cindebinoro berarti menguatkan untuk menyembah dewanya. Jadi dapat disimpulkan bahwa sabuk cindebinoro merupakan pengikat yang mengikat tubuh tokoh wayang agar menjadi kuat selama menjadi seorang umat.

Ketujuh, Gelang susun celumpringan

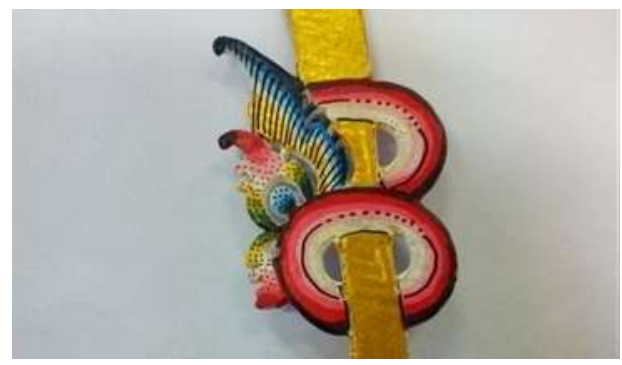

Gambar 15

Gelang susun celumpringan

(Foto oleh Yuni Prastika di Surakarta, 2017)

Menurut Bambang Suwarno gelang susun merupakan hiasan yang melingkari pergelangan tangan secara tersusun, sedangkan celumpringan adalah daun bambu yang kering. Sedangkan makna simbolik dari gelang tersebut adalah sebagai bentuk perlindungan diri. Gelang dan berbagai atribut adalah baju perang. Tepi daun bambu kering pada kenyataanya memiliki ketajaman seperti pisau, dan akan membuat luka jika terkena kulit. Oleh sebab itu gelang tersebut dipakai oleh Kresna wanda rondon. Jika ditinjau dari teori symbol of feeling, maka gelang adalah hiasan yang sudah dipakai oleh manusia sejak zaman dahulu pada pergelangan tanganya. Jika mengatakan tentang gelang persep -si tentang aksesoris akan langsung terpikir pertama kali.

Kedelapan, Supe tajuk sakembaran

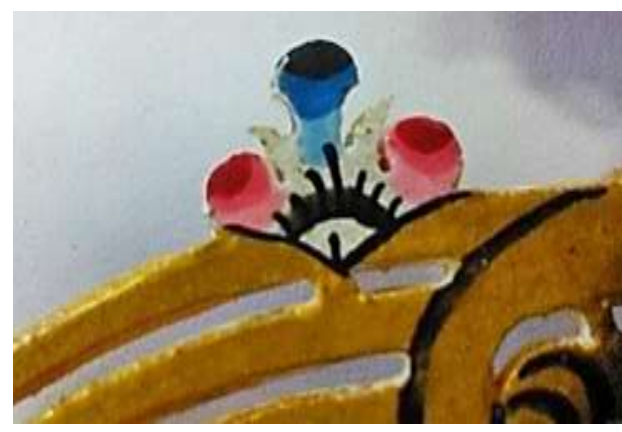

Gambar 16

Supe Tajuk Sakembaran

(Foto oleh Yuni Prastika di Surakarta, 2017)

Merujuk pada teori simbol milik Langer, cincin sering kali dikonsepkan sebagai seperti perhiasan yang berarti, karena dibeberapa kepercayaan, cicin adalah simbolik ikatan cinta. Sedangkan menurut Bambang Suwarno Supe merupakan pengertian dari cincin, sedangkan tajuk sakembaran adalah pengertian dari gunung sapikul. Jadi kesimpulannya cincin tersebut ada- 
lah simbolik dari kekuatan yang begitu besar, karena seperti dapat membawa gunung sapikul pada jari-jari tangannya. Juga sekali lagi membuktikan kekuasaan dari seorang raja.

Sembilan, Binggel keroncong kencono

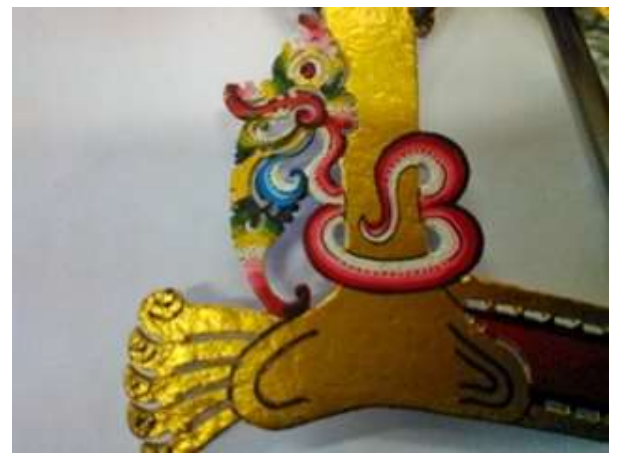

Gambar 17

Binggel keroncong kencono (Foto oleh Yuni Prastika di Surakarta, 2017)

Binggel adalah pengertian lain dari gelang kaki, dalam beberapa tradisi pada seni pertunjukan, jenis gelang kaki ini sering dipakai sebagai aksesoris tambahan pada penari, contohnya pada gelang kaki penari topeng ireng dan jathilan. Menurut Bambang Suwarno keroncong kencono adalah kerincing emas, atau bell emas. Kerincing akan selalu berbunyi setiap melangkah jika memakai. Pemaknaan simbolik dari binggel ini adalah bahwa setiap langkah yang diambil oleh Kresna akan selalu terdengar oleh siapapun. Menanda -kan bahwa Kresna bukan orang yang pengecut dan tidak akan takut. Sedangkan menurut teori symbol of feeling, maka gelang kaki lebih terkenal dikalangan perempuan sebagai perhiasan. Karena jarang ada laki-laki yang menggunakan binggel. Berdasarkan hal tersebut penggunaan binggel dimasa sekarang lebih kepada sebuah fashion semata.

Kesepuluh, Dodot bokongan limar ketangi unthuk banyu.

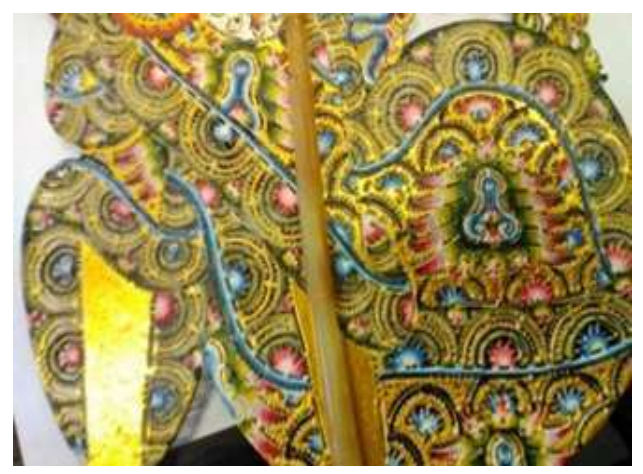

Gambar 18

Dodot bokongan limar ketangi unthuk banyu (Foto oleh Yuni Prastika di Surakarta, 2017)

\section{Menurut Bambang Suwarno} Bokongan adalah bentuk dari kain wayang, Kresna wanda rondon merupakan wayang dengan jenis kain bokongan. limar ketangi adalah jenis limar yang tegak geometris, karena tangi dalam bahasa jawa artinya bidang. 
Sedangkan unthuk banyu menurut Saimono adalah buih dari air. Maka dapat disimbolkan bahwa kain yang dikenakan oleh wayang Kresna tersebut adalah jenis yang menginterpretasikan jenis limar dengan tatahan geometris berpola buih air yang disengaja oleh Saimono untuk menggambarkan riak dari suatu air. Air sendiri memiliki sifat yang dapat berubah sewaktuwaktu dan tidak tentu.

\section{Kesebelas, Awak prodo mas}

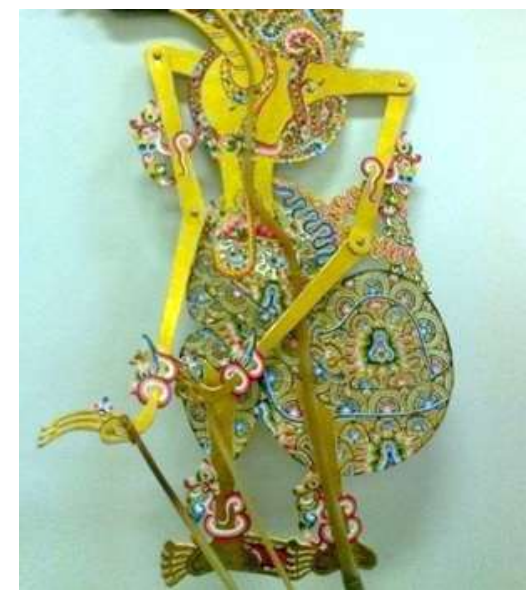

\section{Gambar 19}

Awak Prodo Mas Kresna

(Foto oleh Yuni Prastika di Surakarta, 2017)

Menurut Bambang Suwarno ciri khas dari Kresna wanda rondon adalah tubuhnya yang sedikit lebih gemuk dibandingkan dengan wayang Kresna wanda yang lain. Jika ditinjau dari teori Langer tentang symbol of feeling, tubuh merupakan simbol dari diri seseorang, dan seekor makhluk. Entah itu tubuh yang mati atau tubuh yang hidup. Maka dapat disimpulkan bahwa tubuh dari wayang merupakan interpertasi dari diri wayang tersebut.

Berdasarkan analisis unsur rupa dan simbolik, karakter visual yang terbentuk dari analisis tentang Kresna wanda Rondon jika dilihat dari keseluruhan perabot busana dan bentuk wayang nya adalah bentuk visual dari cerminan visual raja pada wayang kulit purwa. Kresna memiliki Mahkota kencana yang berwarna emas sebagai simbol kekuasaan, berpraba yang berarti beraura cahaya seperti aura yang positif, dengan kalung ulur yang merupakan salah satu ciri dari wayang jenis raja, menggunakan kain bentuk kain bokongan bermakna buih air yang tenang dan beriak jika disentuh, seperti sifat yang tenang tetapi akan berubah jika diganggu.

Menggunakan gelang celumpringan seperti senjata pisau, kelat bahu nagamangsa yang melambangkan tentang kehidupan yang sejati, dapat diartikan juga sebagai Kresna yang mempelajari tentang kebenaran yang mutlak, menjadikannya sosok yang jujur. Binggel keroncong kencono yang menggambarkan tentang bunyi langkah 
Kresna, yang terdengar kemanapun dia melangkah, dapat diartikan juga sebagai setiap langkahnya menjadi membawa perubahan besar hingga selalu menjadi pusat perhatian dalam hal kebaikan, dan cincin tajuk sakembaran yang mesimbolkan lewat jari tanganya sekalipun, Kresna dapat memikul gunung yang berarti dpat memikul tanggung jawab yang besar. Sebagai perabot pelengkap. Serta menggunakan manggaran yang me -miliki bandono, sebagai simbolik pengendalian diri.

Memiliki dominan warna emas pada tubuh dan beberapa perabot pakaiannya, dan warna merah, jingga, biru, hijau, kuning monokrom pada setiap detail perabotnya, juga warna hitam pekat pada bagian wajahnya. Berdasarkan teori warna, dominan warna emas pada Wayang Kresna wandaa rondon memiliki simbol keagungan, dan warna hitam pada wajahnya yang agak menunduk mesimbolkan wibawa. Maka dapat disimpulkan bahwa wayang kulit Kresna wandan rondon memang merupakan jenis wanda wayang kulit Kresna yang mencerminkan keagungan seorang raja dan pemimpin yang beraura positif, tenang, jujur, pembawa perubaha, bertanggung jawab dan bijaksana, serta berwibawa. Berdasarkan uraian diatas maka karakter Kresna wanda rondon layak dijadikan panutan sebagai gambaran dari jiwa pemimpin yang dapat diandalkan.

\section{KESIMPULAN}

Semua tradisi yang dijalankan merupakan upaya dalam konservasi dan revitalisasi wayang kulit purwa yang mulai jarang peminatnya dengan berjalannya waktu. Maka dapat disimpulkan bahwa pembuatan wayang memerlukan kesabaran dan ketekunan. Menatah dan menyungging wayang dapat digunakan sebagai latihan menjaga emosi. Menurut analisis unsur visual dan pemaknaan simboliknya maka dapat disimpulkan karakter yang terbentuk dari wayang kulit Kresna wanda rondon adalah memang merupakan jenis wanda wayang kulit Kresna yang mencerminkan keagungan seorang raja dan pemimpin yang beraura positif, tenang, jujur, pembawa perubaha, bertanggung jawab dan bijaksana, serta berwibawa. Berdasarkan uraian diatas maka karakter Kresna wanda rondon layak dijadikan panutan sebagai gambaran dari jiwa pemimpin yang dapat diandalkan. 


\section{DAFTAR PUSTAKA}

Agus Ahmadi, 2016, Kriya Wayang Kulit Purwa Gaya Surakarta Indentifikasi Pola, Aneka Tatahan dan Sungingannya Cetakan II, Surakarta: ISI Press Surakarta

Amir mertosedono, 1990, Sejarah Wayang Asal-Usul, Jenis dan Cirinya, Semarang: Dahara Prize

Bagyo Suharyono, 2005, Wayang Beber Wonosari, Wonogiri: Bina Citra Pustaka

Dharsono Sony Kartika, 2007, Kritik Seni, Bandung: Rekayasa Sains.

2016, Kreasi Artistik,

Surakarta: LPKBN Citra Sains

KRMT John Tondowidjojo, 2013, Ennegram dalam Wayang Purwa, Jakarta, Gramedia Pustaka Utara

Lexy J. Moleong , 2009, Metodologi Penelitian Kualitatif, Bandung, Remaja Rosdakarya

Marwoto Pengenggak W, 1990, Tuntunan Ketrampilan Tatah Sungging Wayang Kulit cetakan II, Surabaya: Citra Jaya Murti

Matius Ali, 2009, Estetika: Sebuah Pengantar Filsafat Keindahan, Tangerang, Sanggar Luxor

Riziem Aizid, 2012, Atlas TokohTokoh Wayang, Yogyakarta, Diva Press,

Soetarno, 2007, Sejarah Pedalangan, Surakarta: Cendrawasih
Sugiyono, 2013, Metode Penelitian Kuantitatif, Kualitatif dan R\&D, Bandung: Alfabeta

Penelitian Kualitatif, Ban-
dung: Alfabeta

Susilamadya dan Sumanto, 2014, Mari Mengenal Wayang Jilid I: Tokoh Wayang Mahabharata, Yogyakarta: Adi Wacana

Sutopo H.B, 2002, Metode penelitian Kualitatif Dasar Teori dan Terapannya dalam Penelitian edisi 2, Surakarta: Universitas Sebalas Maret

Langer, K. Suzanne, 1988, Problematika Seni diterjemahkan oleh Fx.Widaryanto, Bandung, ASTI Bandung

Bambang Suwarno, 1999, "Wanda Wayang Kaitannya dengan Pertunjukan Wayang Kulit Purwa Masa Kini", Tesis untuk memenuhi S-2, Yogyakarta: Program Pascasarjana Universitas Gadjah Mada

Ma'sumah Cholidiah Dziebany, 2015, "Kajian Visual Figur Bima Wanda Lindu Panon pada Wayang Kulit Purwa Garapan Bambang Suwarno", Skripsi Untuk memenuhi S-1, Malang, Universitas Muhamadiah Malang.

Renda Widhi Andaru, 2015, "Analisis Bentuk Visual dan Makna Simbolik Tokoh Prabu Kresna pada Wayang Kulit Purwa Gaya Surakarta", Skripsi Untuk memenuhi S-1, Surakarta, ISI Surakarta 
Supriyatmono, 2007, "Kajian Makna Simbolik Ragam Rupa Raksasa Brahala dalam Wayang Kulit Purwa Lakon Kresna Duta", Tesis Untuk memenuhi S-2, Surakarta, ISI Surakarta.

Departemen Pendidikan dan Kebudayaan Republik Indonesia alih aksara Moelyono Satronayatmo, 1981, Ebook Wanda ringgit Purwa Milik Keraton Surakarta, Jakarta, Buku Sastra Indonesia dan Daerah

\section{Website:}

Wikipedia, Wayang Purwa, https://id.wikipedia.org/wiki/Wayang _purwa, 01 Maret 2016

Wikipedia, Penelitian Deskriptif, https://id.wikipedia.org/wiki/Peneliti an_deskriptif, 06 April 2016 